\title{
KONTESTASI ENERGI ANTARA MASYARAKAT DESA RANTAU SAKTI DAN PLN DALAM PEMANFAATAN TENAGA LISTRIK DI DESA RANTAU SAKTI, KABUPATEN ROKAN HULU
}

\author{
Geovani Meiwanda \\ Jurusan Administrasi Publik, Fakultas Ilmu Sosial dan Ilmu Politik, Universitas Riau \\ geovani.meiwanda@lecturer.unri.ac.id
}

\begin{abstract}
Desa Mandiri Energi is a program launched by the Central Government through the Ministry of Energy and Mineral Resources, and this program requires active roles from community in its implementation. The village of Rantau Sakti, one of the villages in Tambusai Utara Sub-district, is a village where the successful implementation of Mandiri Energi Village and formed PLT-Biogas Rantau Sakti. Biogas flow was obtained from the waste of Palm Oil which eventually able to become electrical energy for the community in some villages. The running and development of the Desa Mandiri Energi program was in line with the conflict with PLN Rayon Bagan Batu which was adjacent to North Tambusai District. This article will analyze in depth, like a coin that has two sides. On one hand, when the Mandiri Energi program in several places in Indonesia failed, the program succeeded in North Tambusai Sub-district although it proved to be a conflict with PLN. Conflict goes without mediation between the two actors with different perceptions, which indicates the absence of government in the conflict management process.
\end{abstract}

Keywords: Energy, Conflict, and Conflict Management.

\begin{abstract}
Abstrak
Desa Mandiri Energi merupakan program yang dicanangkan oleh Pemerintah Pusat lewat Kementerian Energi dan Sumber Daya Mineral, dan dalam impleementasinya masyarakat tetap dituntut untuk berperan aktif. Desa Rantau Sakti merupakan satu dari sejumlah desa di Kecamatan Tambusai Utara, sebuah desa yang berhasil dalam mengimplementasikan Desa Mandiri Energi dan mendirikan PLT-Biogas Rantau Sakti. Aliran Biogas yang didapatkan dari limbah Kelapa Sawit yang akhirnya mampu menjadi energi listrik. Berjalan dan berkembangnya program Desa Mandiri Energi ini sejalan dengan munculnya konflik dengan PLN Rayon Bagan Batu yang wilayah nya bersebelahan dari Kecamatan Tambusai Utara. Artikel ini akan menganalisis secara mendalam, seperti koin yang memiliki dua sisi. Pada satu sisi, saat program Desa Mandiri Energi dibeberapa tempat di Indonesia gagal, program ini berhasil di Kecamatan Tambusai Utara meskipun ternyata menimbulkan konflik dengan PLN. Konflik berjalan tanpa dilakukan mediasi antara kedua aktor yang berbeda persepsi, yang menunjukan tidak hadirnya pemerintah didalam proses manajemen konflik.
\end{abstract}

KataKunci: Energi, Konflik, dan Manajemen Konflik.

Diterima 16 Februari 2018; Diterima dengan revisi 10 April 2018; Dipublikasikan 1 Mei 2018

2406-9515 (p) / 2528-441X (e)

(c) 2018 Geovani Meiwanda. Dipublikasikan oleh JIAN FIS UNY 


\section{PENDAHULUAN}

Energi listrik merupakan suatu hal pokok yang harus didapatkan dalam kehidupan sehari-hari, bukan hanya hak dari masyarakat perkotaan saja tapi juga masyarakat pedesaan. Fakta nya di Indonesia masih terdapat desa-desa yang belum mendapatkan aliran listrik. Pemerintah Republik Indonesia tentu tidak tinggal diam dalam menyikapi situasi energi listrik namun tetap harus dapat menjaga agar tidak terjadi pembuangan energi kedepannya. Fokus membangun infrastuktur terhadap daerah 3T yaitu terdepan, terluar dan tertinggal mengoptimalkan jaringan listrik. Selain membangun jaringan listrik baru. infrastruktur dipandang sebagai lokomotif pembangunan nasional dan daerah. Pemerintah juga meluncurkan program Desa Mandiri Energi yang harapannya sejumlah desa dengan kriteria tertentu dapat mampu mengaliri listriknya tanpa bergantung kepada PLN atau bahan bakar listrik yang mahal.

Kabupaten Rokan Hulu merupakan salah satu Kabupaten yang ada di Riau yang menyanggupi untuk mengambil Program dari Pemerintah Pusat, yaitu Program Desa Mandiri Energi yang dicanangkan oleh Kementerian Energi dan Sumber Daya Mineral, dengan memanfaatkan energi Biogas. Program
Desa Mandiri Energi ini pun berlandaskan kepada arah Kebijakan Energi Nasional dalam Peraturan Presiden Nomor 5 Tahun 2006, yaitu penyediaan Biofuel minimal $5 \%$ pada tahun 202, natural gas merupakan salah satu pilihan energi yang cukup baik dibandingkan protaleum, ini sudah diterapkan sejumlah negara dikawasan Asia Tenggara (Sovacool, 2009). Salah satu desa yang ada di Kabupaten Rokan Hulu yang berada diperbatasan dengan wilayah tetangga yaitu Kabupaten Rokan Hilir, dan juga selama ini tidak sampai pada jangkauan listrik PLN. Pemanfaatan energi listrik yang didapatkan oleh masyarakat nya hanya dari energi listrik berbahan diesel.

Program Desa Mandiri Energi (DME) tentu memiliki sejumlah kriteria dasar dalam memilih sasaran pengembangannya. Sasaran pengembangan program ini yakni untuk penciptaan lapangan kerja, pengurangan tingkat kemiskinan, dan penyediaan energi di pedesaan. Pengembangan energi di pedesaan harus sejauh mungkin melibatkan peran serta semua masyarakat, dari awal sampai akhir. Karena sasaran akhir nya adalah untuk masyarakat, menurut Narayan dan Singh (2007) searah atau dua arah kausalitas dari pemanfaatan listrik untuk pertumbuhan ekonomi berarti bahwa perekonomian sangat bergantung 
pada pemanfaatan listrik, dan pemanfaatan listrik dapat menghambat penurunan ekonomi pertumbuhan.Maka masyarakat akan merasa ikut memiliki dan bertanggung jawab atas keberlanjutan dari program tersebut.

Program ini bisa berlokasi di desa nelayan, desa tertinggal dan terpencil. Komoditas yang dikembangkan mengacu pada kelayakan agroklimat dan sosial ekonomi setempat. Wilayah pengembangan DME tidak dibatasi oleh wilayah administratif suatu desa. Pengertian desa dalam DME lebih mengacu pada kelayakan teknis dan sosial ekonomis, bukan wilayah administrasi, Kelembagaan dan skala usahanya berbentuk koperasi atau kelompok usaha kecil dan menengah, pemerintah (pusat dan daerah) memberikan bantuan khusus berupa saran produksi (bibit, kebun induk, mesin peralatan, dan sarana lainnya) untuk daerah terpilih.

$\begin{array}{rrrr}\text { Standar } & \text { dan } & \text { kriteria } & \text { yang } \\ \text { disyarakatkan } & \text { dalam } & \text { Program } & \text { Desa }\end{array}$ Mandiri Energi dari Kementerian Energi dan Sumber Daya Mineral tersebut akhirnya sampai kepada Kabupaten Rokan Hulu, dan dari sejumlah Kecamatan yang ada Kecamatan Tambusai Utara lah yang menyanggupi untuk melaksanakan dan mengembangkan Program Desa Mandiri ini. Awal nya peraturan turunan yang diturunkan oleh Bupati yaitu Kecamatan Mandiri Energi namun terhitung pada tahun 2015 dengan Nomor Surat Keputusan Bupati Rokan Hulu Kpts. 671/DISTAMBEN-BE/262/2015 dalam poin ketiga Sasaran Kecamatan Mandiri Energi adalah Desa yang belum terkoneksi dan jauh dari jangkauan jaringan listrik PLN dan Daerah Transmigrasi dalam Kecamatan Tam busai Utara yaitu Desa Rantau Sakti, Desa Mahato Sakti dan Desa Payung Sekaki. Maka terhitung sejak program ini diterima sejak dijalankan tahun 2013 hingga saat ini Desa Rantau Sakti khususnya telah merasakan manfaat dari Program Kementerian Energi dan Sumber Daya Mineral yaitu Desa Mandiri Energi.

Desa Rantau Sakti dan Program Desa Mandiri Energi nya telah berjalan selama lima tahun terakhir ini, dengan memanfaatkan energi biogas dan sudah berhasil mandiri sesuai dengan sasaran tujuan dari Pemerintah Pusat. Dalam proses nya ternyata terdapat gesekan antara keberhasilan program desa mandiri dengan BUMN terbesar pengelola listrik di Indonesia, PLN. Gesekan tersebut pun tidak mampu diambil alih oleh Pemerintaha Daerah nya yaitu Pemerintah Kabupaten Rokan Hulu meski saat ini Indonesia sudah menganut konsep desentralisasi dalam manajemen 
pemerintahannya. Energi merupakan suatu urusan yang menjadi langsung urusan pemerintah pusat yang didalam nya menjadi tanggung jawab pemerintah provinsi untuk membantu dalam proses nya didaerah.

Saat ini dari tiga desa yang telah ditetapkan oleh Keputusan Bupati Rokan Hulu tahun 2015, pada akhirnya yang secara konstan menggunakan dan memanfaatkan energi Biogas hasil limbah sawit hanya Desa Rantau Sakti. Situasi tersebut disebabkan oleh dua desa lain nya disinyalir diintervernsi oleh PLN sebagai pemasok tenaga listrik diwilayah mereka. Konflik sosial muncul karena masingmasing mempertahankan argumentasinya dalam upaya pemanfaatan energi. PLTBG (Bio Gas) Desa Rantau Sakti berhasil mengelola tenaga listrik dari pemanfaataan energi tersebut menjadi listrik, hingga daya yang dihasilkan berlebih.

Kontestasi energi yang terjadi menyebabkan konflik antara dua pihak dari sisi PLTBG Rantau Sakti yang menanggap bahwa program ini adalah bagian dari upaya seluruh masyarakat, dan PLN yang kemudian datang dengan intervensinya memasok tenaga listrik kepada masyarakat. Tulisan ini akan memberikan analisis dan uraian terhadap kontestasi energi yang terjadi, bagaimana ini memunculkan terjadinya konflik sosial dan menajemen konflik yang dilakukan oleh Pemerintah Kabupaten Rokan Hulu untuk mengatasi konflik tersebut.

\section{METODE}

Tulisan ini menggunakan metode kualitatatif, dengan pendekatan deskriptif. Penelitian ini dilaksanakan dengan pendekatan kualitatif, dimana pendekatan kualitatif menurut Burhan Bungin (2011) memiliki tahapan penelitian yang melampaui berbagai tahapan berfikir kritis ilmiah, yang mana seorang peneliti mulai berfikir secara induktif yaitu menangkap berbagai fakta atau fenomena-fenomena sosial melalui pengamatan di lapangan, kemudian menganalisisnya dan berupaya melakukan teorisasi berdasarkan apa yang diamati itu. Peneliti melakukaan penelitian secara objektif terhadap permasalahan penelitian yang ingin diteliti. Pendekatan kualitatif dilakukan melalui wawancara secara mendalam (indept interview) dan FGD kepada informan yang diambil secara purposive sampling terhadap informan-informan yang dianggap mampu menjawab dan membantu peneliti untuk melakukan analisis dalam penelitian ini.

Mattew B. Miles and A. Michael Huberman (1992) menjelaskan dalam analisis kualitatif terdiri dari tiga alur 
kegiatan yang terjadi secara bersamaan, yaitu : Pertama, reduksi data diartikan sebagai proses pemilihan, pemusatan perhatian pada penyederhanaan, pengabstrakan dan transformasi data "kasar" yang muncul dari catatan-catatan tertulis di lapangan. Selama pengumpulan data berlangsung, terjadilan tahapan reduksi yaitu membuat ringkasan, mengkode, menelusur tema, membuat gugus-gugus, membuat partisi dan menulis memo. Reduksi data atau proses transformasi ini berlanjut terus sesudah penelitian lapangan, sampai laporan akhir lengkap tersusun. Kedua, penyajian data merupakan sekumpulan informasi tersusun yang memberi kemungkinan adanya penarikan kesimpulan dan pengambilan tindakan. Sehingga dengan melihat penyajian data, kita dapat memahami apa yang sedang terjadi dan apa yang harus dilakukan. Agar lebih jauh dapat menentukan langkah menganalisis atau mengambil tindakan yang berdasarkan atas pemahaman yang didapat dari penyajian-penyajian data tersebut. Ketiga, penarikan kesimpulan atau verifikasi merupakan suatu tinjauan ulang pada catatan-catatan lapangan atau mungkin menjadi begitu seksama dan makan tenaga dengan peninjauan kembali serta tukar pikiran diantara teman sejawat untuk mengembangkan "kesepakatan intersubjektif" atau juga upaya-upaya yang luas untuk menempatkan salinan suatu temuan dalam seperangkat data yang lain. Singkatnya, makna-makna yang muncul dari data harus diuji kebenarannya, kekokohannya dan kecocokannya atau sering disebut dengan validitas.

\section{HASIL DAN PEMBAHASAN}

Kecamatan Tambusai Utara menyanggupi untuk menjalankan program Desa Mandiri Energi, yang langsung didanai dan dukung penuh oleh Pemerintah Pusat. Seiring dengan berjalannya proses implementasi program ini, terjadilah penyempurnaan dalam pengembangan dan pelaksanaan program Desa Mandiri Energi yang keberhasilannya tentu tidak lepas dari peran dan dukungan penuh dari seluruh masyarakat yang ada di desa tersebut. Bentuk dari partisipasi masyarakat adalah masyarakat menyediakan lahan untuk pelaksanaannya, termasuk kebutuhan lain diluar yang ditanggung oleh pemerintah pusat. Perusahaan besar disekitar desa pun memberi kontribusi terhadap pemanfaatan dari hasil produksinya. PT. Geng merupakan salah satu perusahaan perkebunan Kelapa Sawit yang ada di Kecamatan Tambusai Utara. 
Desa Mandiri Energi yang dikembangkan dan dilaksanakan pada Desa Rantau Sakti yaitu pengembangan energi terbarukan, yang didapatkan dari limbah sawit yang dihasilkan dari salah satu perusahaan besar yang ada disekitar wilayah Kecamatan Tambusai Utara, Kabupaten Rokan Hulu. Energi listrik yang dihasilkan tentunya ramah lingkungan. Kondisi masyarakat pada saat itu masih gelap gulita dan pasokan listrik hanya didapat melalui generator set (genset) dan PLTD dimana ketersediaan listrik dibawah $60 \%$ dengan voltase sampai dibawah 100 volt dan sering terjadi pemadaman bergilir sehingga bisa dikatakan masyarakat yang mampu bisa memperoleh listrik sedangkan masyarakat miskin sama sekali tidak memperoleh listik. Ketersediaan bahan bakar solar juga menjadi penyebab kurangnya pasokan listrik, dan masyarakat harus mengeluarkan biaya antara Rp 350.000500.000/bulan untuk membayar listrik.

Pelaksanaan dan Pengembangan Program Desa Mandiri Energi memiliki dasar kunci pada masyarakat itu sendiri, masyrakat Desa Rantau sakti menyediakan lahan sekitar kurang lebih 2 Ha (Rp 450.000.000) untuk pembangunan Pembangkit Listrik Tenaga Biogas (PLTBG) yang merupakan lahan masyarakat yang dibeli oleh pihak Desa.
Proses pembangunan PLTBG menggunakan dana sekitar 30 Milyar yang berasal dari dana pemerintah melalui Kementrian Energi dan Sumber Daya Mineral, Pemerintah Kabupaten Rokan Hulu dan bantuan swadaya masyarakat. Pembangkit Listrik Tenaga Biogas (PLTBG) ini mulai beroperasi sekitar tahun 2014 dan pada awalnya melayani 1.050 KK dan hingga tahun 2016 jumlah tersebut terus bertambah menjadi 2.232 KK yang tidak hanya berasal dari Desa Rantau Sakti tetapi juga dari Desa Mahato Sakti dan Desa Rantau Kasai.

Pada saat pelaksanaan program desa mandiri energi, muncul sebuah kontestasi konflik pada akhirnya antara PLT Biogas Rantai Sakti dan PLN Rayon Bagan Batu Rokan Hilir. Kecamatan Tambusai Utara dibagi atas 3 Desa yang menjadi daerah prioritas melalui surat keputusan No.671 /DISTAMBENBE/262/2015 tanggal 11 Mei 2015 tentang penetapan Desa dalam Kecamatan Tambusai Utara sebagai Desa Mandiri Energi meliputi Desa Rantau Sakti, Desa Mahato Sakti dan Desa Rantau Kasai.

Setelah berjalan, komisi dari tahun 2014 sampai dengan bulan September tahun 2016, konfilik tersebut PLN rayon Bagan Batu dari daerah Pujud, Kabupaten Rokan Hilir. PLN Rayon Bagan Batu memberikan aliran listriknya DK 5 (Desa 
Suka Damai) berbatasan dengan Mahato Sakti. Mahato Sakti merupakan desa yang berada di wilayah Kecamatan Tambusai Utara, yang selama ini mendapatkan aliran listrik dari PLT Biogas Rantau Sakti . Hal tersebut menyebabkan terjadinya konflik antara pihak pengelola PLTBG dengan PLN dan sudah dilakukan rapat di berbagai forum namun tidak memperoleh titik temu, dikarenakan Pemerintahan Kabupaten Rokan Hulu tidak memiliki kapasitas dan tupoksi dalam urusan pengelolaan energi (tidak ada perpanjangan urusan pada tingkat Kabupaten).

Konflik muncul pada situasi Program Desa Mandiri Energi yang telah berhasil dalam melakukan pengembangan tenaga listrik yang ramah lingkungan dan masyarakat sebagai motorik utamanya. Sebuah konflik yang terjadi tidak lepas dari tiga domain besar yang terjadi didalamnya, yang pertama perbedaan dari struktur. Saat ini yang menjadi perebutan adalah tenaga listrik, yang awalnya desadesa tersebut pada Kecamatan Tambusai Utara tidak mendapatkan aliran listrik dari PLN, sehingga masyarakat menggunakan diesel dengan biaya sangat tinggi dan listrik hanya bisa menyala pada waktuwaktu tertentu. Masuknya Program Desa Mandiri Energi, dan pada akhirnya berhasil membuat perusahan PLT Biogas sendiri merupakan awal dari perebutan lahan usaha. PLN dan PLTB merupakan dua perusahaan yang dalam lahan usaha yang sama, yaitu tenaga listrik, namun memiliki perbedaan struktur didalamnya.

Perbedaan struktur tersebut akan mengacu kepada perbedaan persepsi yang muncul, dari aktor yang berbeda. PLT Biogas merupakan aktor yang lahir dari Program Desa Mandiri Energi yang merasa terganggu ketika muncul nya PLN Rayon Bagan Batu yang tiba-tiba muncul memberikan aliran listrik dan membuat masyarakat dari salah satu desa pada akhirnya memilih untuk menggunakan listrik PLN. Perkembangan selanjutnya yang muncul adalah dalam satu desa terdapat dua tiang aliran listrik dengan jarak yang berdekatan. Situasi ini semakin memperburuk konflik yang terjadi antara PLT Biogas dan PLN dari Rayon Bagan Batu.

Dalam manajemen konflik menurut Goldberg \& Brett (1983), mediasi akan menghasilkan sesuatu yang baik jika didukung dengan partisipasi tinggi dari pihak yang berkonflik. Menganalisis dari yang dikemukakan oleh Goldberg \& Brett dibutuhkan sebuah perencanaan dalam manajemen sebuah konflik. Perencanaan yang dimaksud, tentu membuat sistem yang menjadi sebuah resolusi, yaitu mediasi. Sebuah 
mediasi tentu harus dapat mengacu kepada beberapa hal untuk membentuk sebuah resolusi, yakni mampu menjadi proses yang cepat tanggap, memiliki tujuan, dan pertimbangan yang matang.

Mediasi yang dapat dilakukan antara PLT Biogas dan PLN Rayon Bagan Batu, menjadi terhambat karena meski PLT Biogas berada dibawah wilayah administratif pemerintahan Kabupaten Rokan Hulu namun pemerintahan Kabupaten Rokan Hulu tidak memiliki wewenangan dalam urusan energi karena leading sector perpanjangan tangan dari Pemerintahan Pusat berada pada tingkat Provinsi. Meskipun situasi ini sudah dilemparkan kepada tingkat Pemerintah Provinsi Riau, tetapi tidak dapat memberikan ruang untuk melakukan mediasi, agar tidak terjadi dua persepsi berbeda yang memicu konflik.

Potensi besar yang telah berhasil diciptakan oleh Kementerian Energi dan Sumber Daya Mineral Republik Indonesia, namun ternyata memberikan sebuah konflik terhadap masyarakat desa. Pengelola PLT Biogas Rantau Sakti dan Desa Rantau Sakti memiliki komitmen untuk terus mengelola teknologi listrik biogas ini, karena menurut pengelola PLT Biogas merupakan aset negara yang sangat berharga. PLT Biogas dan masyarakat desa tentu mengharapkan kehadiran dan peran negara (pemerintah) untuk dapat memberikan solusi, karena program ini merupakan bentuk pembangunan infrastuktur listrik yang merupakan kerjasama antara pemerintah pusat/ daerah, pihak swasta dan masyarakat. Hingga saat ini tidak ada penyelesaian dalam format manajemen konflik yang terjadi antara dua aktor tenaga listrik ini

Konflik yang terjadi sama persis dengan yang dikemukakan oleh Himes (1980), dimana konflik pasti muncul ketika sebuah tujuan menjelma atas sebuah kekuasaan, kekuatan dan sumber daya. Konflik muncul antara PLT Biogas dan PLN muncul ketika, tenaga listrik dari Biogas ini berjalan dengan stabil untuk masyarakat. Sesuatu yang tadi nya dianggap kecil ketika besar maka akhir nya diperebutkan, dan yang membuat eskalasi konflik disini terlihat monoton adalah dikarenakan tidak ada nya mediasi untuk menyelesaikan konflik ini. Masingmasing aktor membenarkan pendapatnya tanpa penyelesaian. Dalam perspektif administrasi yang dipaparkan oleh Rosenbloom (1983), resolusi sebuah konflik tidak akan lepas dari manajerial, hukum dan politik. Tidak hadirnya sebuah negara secara implisit tergambar dari apa yang dikemukakan oleh Rosenbloom 
dalam sebuah resolusi konflik secara administrasi.

\section{SIMPULAN}

Program Desa Mandiri Energi yang dicanangkan mungkin pada beberapa daerah tidak berjalan dengan baik, tetapi tidak pada Kecamatan Tambusai Utara Kabupaten Rokan Hulu. PLT Biogas dapat berjalan dan menjadi mandiri mampu memberikan aliran listrik untuk masyarakat. Keberhasilan ini tidak lepas dari partisipasi masyarakat yang sangat tinggi. Namun keberhasilan pembangunan PLT Biogas memunculkan konflik dengan PLN Rayon Bagan Batu. Pemerintah Daerah Kabupaten Rokan Hulu maupun Pemerintah Provinsi Riau tidak bisa melakukan manajemen konflik untuk menghadirkan solusi yang cepat tanggap, memiliki tujuan dan pertimbangan yang matang dalam format mediasi.

Gambaran pada artikel ini mampu mendeskripsikan adanya sebuah kebijakan yang pada awalnya bertujuan untuk menghadirkan pembangunan infrastruktur bagi masyarakat yang selama ini tidak mendapatkan aliran listrik, hingga berhasil dan masyarakat juga menjadi mandiri energi, ternyata menimbulkan konflik pada akhirnya. Konflik dapat terjadi baik pada level makro maupun level mikro itu sendiri (Lan, 1997). Namun pada akhirnya terdapat tiga hal yang lahir ketika konflik muncul : pertama, konflik akan membuat stabilitas dalam sebuah grup maupun personal untuk mampu semakin memperkuat kapabilitasnya. Kedua, konflik menjadi alat tes untuk grup atau individu sendiri agar mampu membuat inovasi, perubahan serta kemajuan. Ketiga, konflik dapat mempererat stabilitas dan integrasi dengan masyarakat.

\section{DAFTAR PUSTAKA}

Burhan Bungin., 2011. Penelitian Kualitatif : Komunikasi, Ekonomi, Kebijakan Publik dan Ilmu Sosial Lainnya., Edisi Kedua., Kencana Prenada Media Group., Jakarta.

Creswell W. John., 2014. Research Design : Pendekatan Kualitatif, Kuantitatif dan Mixed., Pustaka Pelajar., Yogyakarta

Goldberg, Samuel. B and William P. Hobgood. 1987. Mediating Groevences: A Cooperative Solution. Washington, DC: Bureau of Labor Management Relations and Cooperative Programs, U.S. Departement of Labor.

Himes, Joseph. 1980. Conflict and Conflict Management. Athens, GA: University of Georgia Press.

Lan, Zhiyong. 1997. A conflict Resolution Approach to Public Administration. Public Administration Review; Jan/Feb 1997; 57.

Narayan, P.K., and Singh, B. (2007). The Electricity Consumption and GDP Nexus Dynamic Fiji Islands. Energy 
Economics, 29, 1141-1150.

Roseenbloom, David. 1993. Public Administration Theory and The Separation of Power. Public Administration Review 43 (3): 219227.

Sovacool, Benjamin K. 2009. Reassessing Energy Security and the Trans-ASEAN Natural Gas Pipeline Network in Southeast Asia. Pacific Affairs, Vol. 82, No. 3 (Fall, 2009), pp. $467-486$ 